\title{
Multimodalidade e Letramento Visual na sala de aula de Língua Espanhola: análise de uma atividade de produção escrita
}

\section{Multimodality and Visual Literacy in the Spanish Language classroom: analysis of a written production activity}

\author{
Michelle Soares Pinheiro* \\ Universidade Estadual do Ceará \\ Fortaleza, Ceará / Brasil
}

\begin{abstract}
RESUMO: Este trabalho tem, por objetivo, analisar a multimodalidade e o letramento visual de alunos do curso de Espanhol do Núcleo de Línguas da Universidade Estadual do Ceará (UECE), ao ressignificarem um texto multimodal selecionado para a compreensão em produções escritas. O corpus coletado consiste de 18 (dezoito) textos escritos por alunos de língua espanhola e foi analisado à luz dos pressupostos teóricos da multimodalidade e do letramento visual de Kress e van Leeuwen $(1996,2006)$, no que diz respeito às metafunções e à análise da imagem, segundo a Gramática do Design Visual. Nesse sentido, almejamos mostrar como a produção dos textos pode revelar indícios de letramento visual dos alunos no contexto de ensino e aprendizagem nas aulas de Língua Espanhola.
\end{abstract}

PALAVRAS-CHAVE Multimodalidade; Letramento Visual; Texto Multimodal; Língua Espanhola.

\begin{abstract}
This paper aims to analyze the multimodality and visual literacy of Spanish language students enrolled at the Language Center from the State University of Ceará (UECE), Fortaleza, Brazil, by making meanings in written productions based on a selected multimodal text for comprehension. The corpus consists of eighteen texts written by students studying Spanish, and the texts were analyzed in the light of theoretical principles of multimodality and visual literacy theory proposed by Kress and Van Leeuwen (1996, 2006) regarding metafunctions and image analysis, as set forth in The Grammar of
\end{abstract}

\footnotetext{
* michelle040481@hotmail.com

Mestranda em Linguística Aplicada pelo Programa de Pós-graduação em Linguística Aplicada da Universidade Estadual do Ceará.
} 
Visual Design. In this regard, we intend to show how the production of texts may reveal signs of students' visual literacy in the contexts of teaching and learning in Spanish language classes.

KEYWORDS: Multimodality; Visual Literacy; Multimodal Text; Spanish Language.

\section{Introdução}

A pluralidade de usos da linguagem, em diferentes contextos sociais, tem estimulado estudiosos da educação e da linguagem a desenvolverem pesquisas para entender o uso das novas práticas de linguagem na formação dos aprendizes. Uma dessas práticas, seja na forma impressa seja na forma digital, é o uso do texto multimodal, em que os significados são construídos pela combinação de mais de um modo semiótico. Como o texto multimodal (aqui considerado como a integração do uso da linguagem verbal e da linguagem visual) está presente nos materiais didáticos (em nosso caso particular, em língua estrangeira), e exige por parte dos estudantes o domínio de habilidades específicas para compreender essas formas de comunicação. Estudos sobre multiletramentos (COPE; KALANTZIS, 2000), novos letramentos (LANKSHEAR; KNOBEL, 2003), letramento visual (STOKES, 2002; SERAFINI, 2014; BAMFORD, 2003), letramento multimodal (KRESS; VAN LEEUWEN, 1996, 2006; WALSH, 2011) têm sido realizados para compreender como os alunos desenvolvem os letramentos na leitura de textos multimodais.

Nesse sentido, este artigo tem como principal objetivo relatar uma experiência de sala de aula de língua estrangeira com 18 (dezoito) alunos do $5^{\circ}$ semestre de Espanhol do Núcleo de Línguas da Universidade Estadual do Ceará (UECE), realizada com a leitura de um texto multimodal do livro didático de Língua Espanhola adotado em sala de aula. A relevância desta pesquisa encontra-se na necessidade de se utilizar uma abordagem pedagógica para fomentar o letramento visual dos alunos, transcendendo à mera leitura da linguagem verbal. A referida experiência foi embasada na teoria de Multimodalidade de Kress e van Leeuwen (1996, 2006). Dessa forma, pretendemos mostrar que uma atividade realizada em sala de aula pode tornar-se um momento produtivo de aprendizagem, o que permite que sejam trabalhadas as quatro habilidades comunicativas (leitura, escrita, oralidade e audição) em língua estrangeira. Porém, neste relato de experiência, focamos nas habilidades leitora e escrita, cujo corpus 
é constituído das redações dos alunos baseadas em um texto multimodal do livro Aula Internacional 3 (livro adotado pela referida instituição de ensino). Assim, analisamos as metafunções representacional, interativa e composicional da Gramática do Design Visual (GDV), postulada por Kress e van Leeuwen $(1996,2006)$, nas produções dos alunos, observando-se quais aspectos da Gramática do Design Visual foram observados e mencionados por eles em relação à imagem.

\section{Referencial teórico}

Muitas formas de linguagem escrita contemporânea não podem ser adequadamente entendidas se não considerarmos, também, imagens, layout, tipografia, cor, além da linguagem escrita. Estas constatações levaram ao desenvolvimento do campo de estudo para investigar as propriedades comuns, bem como as propriedades distintas na integração de diferentes modos semióticos e na maneira como eles se integram nos textos multimodais e também nos eventos comunicativos. $\mathrm{O}$ termo multimodalidade surgiu na década de 1920, associado ao campo da Psicologia da Percepção, denotando o efeito que diferentes percepções sensoriais têm umas sobre as outras, mas o sentido do termo foi ampliado por linguistas e analistas do discurso, para significar o uso integrado de diferentes recursos comunicativos, tais como a linguagem escrita, a imagem, o som e a música em textos multimodais e eventos comunicativos (VAN LEEUWEN, 2011).

Kress e van Leeuwen $(1996,2006)$ consideram que toda forma de comunicação é multimodal, porque, nos contextos sociais concretos, ou seja, nas práticas sociais com o objetivo de se comunicar, as pessoas se utilizam de formas de comunicação em que diversos modos semióticos se integram. Assim, a multimodalidade é uma perspectiva teórica baseada nos estudos linguísticos e na semiótica social, que afirma que os significados comunicativos são construídos, compartilhados, desafiados por meio do uso de vários modos, dentre os quais a escrita, a fala, a imagem, o som, o gesto, a tipografia, a imagem em movimento (CALLOW, 2014).

A multimodalidade entende que todos os modos têm sido influenciados, como a linguagem verbal, pelos usos sociais, culturais e históricos para realizar funções sociais. A interação entre os modos é significativa para a construção de sentido nos textos. Considerando o fato de que os textos são multimodais, para entendê-los, parece ser necessário que as pessoas tenham habilidades que ultrapassem as competências comunicativas 
de ler e escrever, mas também devem englobar a habilidade de ler imagens. Assim, é necessário que os alunos desenvolvam o letramento visual, que se relaciona diretamente com o conceito de multiletramentos, no que tange à "multiplicidade cultural das populações e a multiplicidade semiótica de constituição dos textos" (ROJO, 2012, p. 13).

Com o advento das tecnologias da informação e da comunicação, o termo "letramento" passou a assumir novos sentidos, de modo que surgem novas denominações. Na década de 1980, o termo surgiu para dar sentido à alfabetização atrelada às práticas sociais. Dessa forma, o letramento ultrapassa o simples ato de ler e escrever, pois se dirige à inserção em situações ou práticas sociais de leitura e escrita, atendendo-se a demandas e exigências da própria sociedade contemporânea capitalista.

É esse, pois, o sentido que tem letramento, palavra que criamos traduzindo "ao pé da letra" o inglês literacy: letra-, do latim littera, e o sufixo -mento, que denota resultado de uma ação (como, por exemplo, em ferimento, resultado da ação de ferir). Letramento é, pois, o resultado da ação de ensinar ou de aprender a ler e escrever: o estado ou a condição que adquire um grupo social ou um indivíduo como consequência de ter-se apropriado da escrita (SOARES, 1998, p. 18 - grifos da autora).

Kleiman (1999) também relaciona o letramento às práticas sociais. No entanto, a autora vincula-o mais à escrita, enquanto sistema simbólico e como tecnologia em contextos específicos para atender a objetivos específicos. Assim, Kleiman (1999) frisa que, no decorrer da segunda metade do século XX, havia a dicotomia entre o alfabetizado e o não alfabetizado (ou analfabeto, termo mais pejorativo e estigmatizado, em nosso ponto de vista), apenas vislumbrando a aquisição da leitura e da escrita, mas não concebia outros tipos de habilidades ligadas a esta última.

O letramento evidencia-se como uma prática discursiva de um grupo social determinado, que atribui à escrita a função de "tornar significativa essa interação oral, mas não envolve, necessariamente, as atividades específicas de ler e escrever" (HEATH, 1982, apud KLEIMAN, 1999, p. 18). Para Lemke (2010, p. 455), "letramentos são legiões. Cada um deles consiste em um conjunto de práticas sociais interdependentes que interligam pessoas, objetos midiáticos e estratégias de construção de significado”. Dessa forma, vemos que o conceito de letramento é dinâmico e vem sendo (re)construído ao longo do tempo e nos mais diversos contextos sociais. 
Em 1994, um grupo de educadores de vários países, autodenominados de The New London Group, reúne-se em New London, New Hampshire, Estados Unidos para discutir e repensar o ensino e uma pedagogia de letramento (devido às mudanças percebidas com a globalização, a tecnologia e a diversidade social) e publica um livro em 1996 com as reflexões sobre multiletramentos. O foco das discussões era acerca do que é ser letrado e das pedagogias necessárias para o letramento. Esses educadores lançam o termo "multiletramentos", que surge em resposta a uma preocupação sobre como o ensino do letramento pode preparar os estudantes para atuar em um mundo de constante mudança, em que eles estão engajados. O termo "multiletramentos" evoca uma série de letramentos e práticas de letramentos - usadas em todos os setores da vida - e como estas práticas podem ser similares e diferentes. Segundo os estudiosos do The New London Group (1996), ser multiletrado significa ser cognitiva e socialmente letrado, ao usar textos de qualquer natureza: impresso, oral e eletrônico. Significa, também, ser criticamente letrado, ter habilidades para analisar textos, identificar suas origens e sua autenticidade, entender como os textos têm sido construídos a fim de perceber suas lacunas, seus silêncios e suas ideologias.

Considerando a discussão dos educadores do New London Group (1996), na sociedade contemporânea, qualquer pessoa precisa ser multiletrada, porque as práticas sociais assim o exigem. Uma dessas práticas sociais é entender e produzir textos visuais/multimodais. Já que, neste estudo, estamos investigando como os alunos constroem significados a partir de um texto visual/multimodal, precisamos discutir a noção do que seja letramento visual/multimodal. Ser letrado visual significa ter não somente a habilidade de produzir e ler/codificar experiências visuais construídas, mas também ter a consciência de si e das representações, em ambos, espaço e tempo, situadas em um modelo social, cultural, histórico e político. Assim, o letramento visual pode ser definido como a "habilidade de 'ler', interpretar e entender informação apresentada em imagens gráficas e pictóricas" (WILEMAN, 1993, p. 114). Nesse sentido, ler imagens gráficas pode ser a leitura de uma tabela, de um gráfico com percentagens e símbolos, dentre outros, enquanto ler imagens pictóricas pode ser ler/ver e interpretar uma foto numa capa de revista, por exemplo. Dessa forma, acreditamos que ler imagens é também perceber as intencionalidades dos produtores deste texto multimodal como também os discursos que passam por meio dessa imagem, além de 
compreender a relação que os elementos imagéticos podem assumir quando associados a elementos textuais/escritos.

Se pensarmos que os materiais de ensino em língua estrangeira são ricos em textos visuais/multimodais (fotos, mapas, gráficos, propagandas, tirinhas e outros), então, o letramento visual/multimodal se faz importante no processo de ensino-aprendizagem em Língua Espanhola, uma vez que os alunos, na maior parte das vezes, almejam utilizar o conhecimento comunicativo nas mais diversas práticas discursivas. Em meio a tantos atrativos da língua espanhola, percebemos, a partir da nossa experiência docente no Núcleo de Línguas da UECE, que a maioria dos alunos se sente atraída por textos multimodais com predominância de elementos imagéticos, em especial quando estes são imagens da Espanha ou de países onde se fala o Espanhol. Por isso, os textos visuais causam os mais variados efeitos de sentido no processo de aprendizagem dos alunos. Eles se sentem motivados com (a partir de) textos imagéticos ou multimodais, de modo que o letramento visual surge como estratégia ou ferramenta didática para trabalhar ideologias, conceitos e habilidades. A esse respeito, Callow (1999) afirma que:

[e]nquanto que o termo 'visual' tornou-se mais comum em aulas de letramento ao longo dos últimos cinco anos, o termo 'leitura' agora é definido de forma mais ampla para englobar textos escritos e visuais. Ler textos escritos e imagens visuais tem semelhanças. Ambos são processos dinâmicos, que envolvem não apenas o texto (escrito ou visual), mas a pessoa que lê/vê, os autores, e o contexto cultural mais amplo dos três. Ambos envolvem trazer experiência de vida e conhecimento prévio sobre o que é lido e visto. Ao contrário dos textos escritos, alguns dos padrões e estruturas de imagens visuais permanecem implícitos e inexplorados por muitos leitores experientes, jovens e velhos. Desenhando os paralelismos com a leitura de um texto escrito, lembra-nos da importância de se compreender e explorar todas as facetas que fazem parte do letramento visual (p. 2). ${ }^{1}$

\footnotetext{
1 'While the term 'viewing' has become more common in literacy classrooms over the last five years, the term 'reading' is now defined more broadly to encompass written and visual texts. Reading written texts and visual images have similarities. They are both dynamic processes, which involve not only a text (written or visual) but the person reading / viewing, the authors, and the wider cultural context of all three. Both involve bringing life experience and background knowledge to what is read and viewed. Unlike written text, some of the patterns and structures of visual images remain implicit and unexplored by
} 
Callow (1999), além de definir letramento visual, enfatiza a importância deste na sala de aula. $\mathrm{O}$ autor esclarece que os textos multimodais também não são uma novidade como estratégia de ensino, pois tanto professores como alunos já tiveram contato com livros paradidáticos infantis extremamente multimodais, bem como diariamente eles têm contato com outras formas de comunicação multissemiótica (televisão, rádio, desenhos, esculturas, sites de Internet, dentre outras). Para o autor, a multimodalidade descreve abordagens que entendem a comunicação e a representação como algo que transcende a linguagem verbal, em virtude de atender a toda uma gama de formas comunicacionais utilizadas pelas pessoas, tais como imagem, gestos, olhar (vetor), postura e as relações entre eles.

Na concepção de Almeida (2009), o letramento associado ao visual permite que o professor amplie as possibilidades pedagógicas e que os alunos desenvolvam melhor sua capacidade crítica da realidade. Assim, as imagens não servem apenas como entretenimento, pois a estrutura visual pode comunicar significados políticos e sociais. "Assim como o código semiótico da linguagem, o código das imagens também representa o mundo (de maneira concreta ou abstrata), constrói relações sociointeracionais e constitui relações de significados a partir do papel desempenhado por seus elementos internos" (ALMEIDA, 2009, p. 178). As imagens, conforme Kress e van Leeuwen $(1996,2006)$, representam a relação entre as pessoas, os lugares e as coisas retratadas aliadas ao conjunto de concatenações que podem existir entre as imagens e os leitores.

Assim, para Kress (2003), um texto multimodal é entendido como o resultado de uma ação social, com qualquer instância de comunicação em qualquer modo ou combinação de modos. As imagens visuais, como a linguagem verbal e todos os modos semióticos, são socialmente construídas. E, na esteira de Callow (1999, 2005), podemos dizer que os professores devem instigar os alunos i) a aprenderem imagens, que representam coisas que vemos ou pensamos; ii) a aprenderem, por meio das imagens, temas na área de ciência, literatura, religião, história e cultura; e iii) a aprenderem sobre imagens, significados ou os sentidos explícitos ou implícitos.

many experienced viewers, young and old. Drawing the parallels with reading written text reminds us of the importance of understanding and exploring all the facets that are part of visual literacy" (CALLOW,1999, p. 2). Todas as traduções dos autores citados neste artigo são de nossa inteira responsabilidade. 
A Gramática do Design Visual de Kress e van Leeuwen (1996, 2006) adota a organização metafuncional, baseada na teoria de Halliday (Gramática Sistêmica Funcional), que mostra como os significados são construídos por meio das seguintes metafunções: representacional (ou ideacional), interativa (ou interpessoal) e composicional (ou textual). A metafunção representacional diz respeito às estruturas que representam, de maneira visual, a natureza de eventos, objetos e participantes envolvidos e representados, bem como as circunstâncias. Ou seja, reflete as relações construídas ao mostrar o que está acontecendo na imagem ou no texto multimodal. A metafunção interativa apresenta a relação entre os participantes, em que "recursos visuais constroem a natureza das relações de quem vê e o que é visto" (FERNANDES; ALMEIDA, 2008, p. 12). Já a metafunção composicional serve para analisar as imagens quanto à estrutura e ao formato do texto, isto é, podemos captar significados por meio da distribuição do valor da informação ou da saliência de alguns elementos do texto imagético.

De acordo com Kress e van Leeuwen (1996, 2006), a linguagem visual não serve apenas de mero complemento da linguagem verbal, mas as imagens se configuram como um forte veículo de comunicação e de informação, pois nem sempre a imagem transmitirá a mesma mensagem que o texto escrito. Assim, nossa pesquisa partiu da curiosidade de investigar a interpretação em um texto escrito que os alunos do $5^{\circ}$ semestre fizeram do texto multimodal selecionado, o qual estava inserido em uma das aulas rotineiras do curso.

\section{Os caminhos metodológicos}

Inicialmente, partimos de uma pesquisa analítico-discursiva, de natureza qualitativa, justificada pelo olhar investigativo em meio à prática docente de ministrar aulas de língua espanhola em um curso de extensão. Com isso, almejamos perceber como o aluno desenvolve o letramento visual/multimodal no processo de ensino-aprendizagem.

Nessa linha de raciocínio, começamos com a pesquisa bibliográfica ou revisão de literatura, a qual, para Laville e Dionne (1999), consiste em localizar todas as pesquisas relacionadas com a temática estudada para fundamentar, teoricamente, o aparelho conceitual. Em seguida, analisamos, de forma qualitativa, as redações escritas dos alunos como resposta à compreensão de um texto multimodal (linguagens verbal e visual) 
selecionado do livro didático adotado em sala de aula. Por meio da análise qualitativa das 18 (dezoito) composições escritas, organizamos e analisamos os dados que faziam referência às categorias das metafunções da GDV. Salientamos que 22 (vinte e dois) alunos do $5^{\circ}$ semestre de Língua Espanhola foram devidamente informados e orientados sobre a pesquisa e deixamos facultativa a participação dos alunos, dentre os quais 18 (dezoito) alunos de nível intermediário se comprometeram a participar, os quais assinaram um termo de compromisso livre e esclarecido, exigência para garantir o caráter ético adotado neste estudo. Os alunos participantes foram identificados pelas iniciais de seus respectivos nomes nas composições escritas, de maneira a manter o sigilo e a ética no uso e na divulgação dos dados.

Convém informar, ainda, que houve uma explicação prévia para os alunos sobre a atividade a ser desenvolvida, que seria a leitura e a compreensão de um texto multimodal da unidade 5 do livro Aula Internacional 3, utilizado por eles. O texto que faz parte da atividade tem como tema os Direitos Humanos, em especial, em prol da igualdade em relação à mulher. Essa tarefa foi solicitada para ser realizada em casa. Sem nenhuma explanação prévia acerca das metafunções da Gramática do Design Visual, esclarecemos que cada aluno poderia expor sua interpretação subjetiva acerca do texto imagético, não havendo interpretação certa ou errada nesta atividade. No entanto, almejávamos perceber como estava o letramento visual/multimodal dos estudantes. Foi dado o prazo de uma semana para os alunos realizarem a atividade proposta e devolverem as redações produzidas, já que a aula acontece somente uma vez por semana.

Os estudantes fizeram as redações em língua espanhola, porém não nos preocupamos em fazer correções de formas gramaticais, lexicais, textuais e ortográficos usadas de maneira indevida. A ideia era examinar que aspectos os estudantes enfatizariam na construção de sentidos, com base na leitura do texto multimodal em seus textos. Por último, à luz das categorias da GDV e de conceitos de letramento visual discutidos no referencial teórico deste artigo, analisamos os textos escritos elaborados em língua espanhola pelos alunos com relação ao texto imagético.

\section{Análise do texto multimodal do livro didático e dos textos escritos pelos alunos}

Nesta seção, apresentamos o texto multimodal, analisado à luz da GDV, e as composições escritas dos alunos participantes do estudo, que são 
analisadas à luz da teoria de Kress e van Leeuwen (1996, 2006), no tocante às funções representacional, interativa e composicional. Ressaltamos que selecionamos as passagens mais relevantes e significativas das produções escritas dos alunos para ilustrar a análise do texto multimodal feita por eles mesmos e que também evidenciam o letramento visual/multimodal deles.

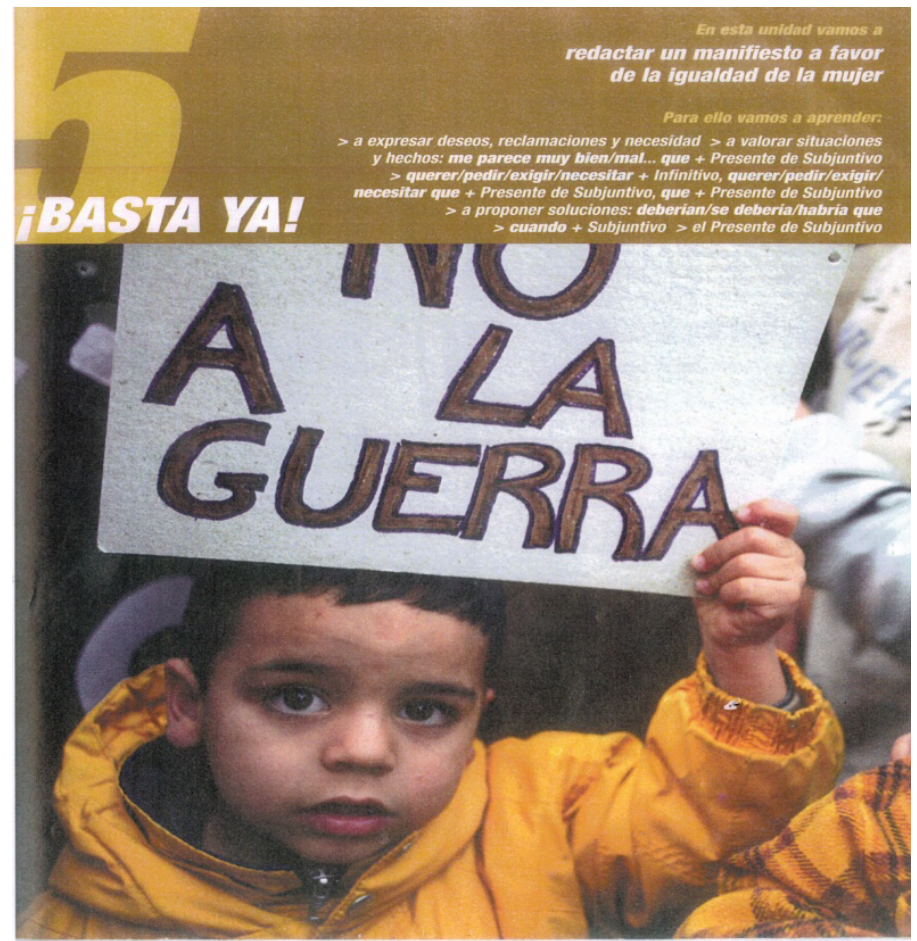

FIGURA 1 - No a la guerra.

Fonte: SORIANO (2006, p. 41)

Analisando o texto multimodal em foco, com base na teoria de multimodalidade de Kress e van Leeuwen (1996, 2006), e, tomando como referência para análise a Gramática do Design Visual, iniciamos pela função representacional, em que os sistemas semióticos (aqui nos referimos às linguagens verbal e visual) têm meios de representar os objetos em sua relação com o mundo. Objetos, pessoas e lugares, mostrados em uma estrutura visual, são denominados de participantes representados (pessoas, lugares ou objetos), que são os sujeitos da comunicação. Assim, as estruturas visuais e verbais, entendidas como sistemas semióticos, compartilham 
características comuns e constituem meios de representação e de produção de significados em contextos culturais.

Esta função, para os autores mencionados, compreende dois processos: narrativo e conceitual. O processo narrativo se realiza quando há ocorrência de ações e reações, percebidas por linha de inclinação ou vetores que conectam os elementos representados na imagem. Os processos narrativos representam os participantes visuais em movimento(s) de ação, em termos de feitos e acontecimentos dinâmicos. O processo conceitual representa os participantes em termos de sua essência: em relação à sua classe, à sua estrutura ou ao seu significado. São representados de maneira mais estática, na medida em que não possuem ações expressas por vetores. No texto analisado, constatamos que há um processo narrativo em que o participante principal, uma criança, exerce a função de ator, cuja ação é segurar um cartaz com uma mensagem de paz, e, embora não se perceba a circunstância da situação, a criança parece estar participando de uma manifestação pública. Por não haver uma interação da criança com outro participante na imagem, a ação é caracterizada por um processo não transacional. O olhar da criança é direcionado para algo fora da imagem.

Já a função interativa abrange estratégias de aproximação ou afastamento entre o produtor do texto e o leitor/observador. Este último, que se encontra fora da imagem, objetiva, dessa maneira, criar uma espécie de relação ou vínculo afetivo, de acordo com Kress e van Leeuwen (1996, 2006). Pela função interativa, deduzimos que há uma demanda, ou seja, o menino representado nos impõe ou nos pede uma reação. Segundo Almeida (2008), a demanda ocorre quando o participante representado olha diretamente o leitor/observador como se o convidasse para interagir com ele. Dessa forma, predomina uma demanda por parte do produtor, o qual tenta criar uma relação imaginária de contato entre o participante representado (o garoto) e o participante interativo (o leitor). Para Callow (1999, p. 9), "uma pessoa que olha no olho em um sentido demanda atenção"'. Em nossa concepção, a imagem do garoto exige uma "resposta" do leitor, instigando uma sensibilização em prol da paz e, ao mesmo tempo, há um apelo emocional, pois a criança representa a inocência, talvez perdida, em decorrência da violência e das guerras. Nossa análise sobre esse olhar de

2 "[...] a person who looks you in the eye in a sense demands your attention" (CALLOW, 1999, p. 9) 
demanda foi percebida no discurso dos alunos por meio de suas produções escritas, tais como: "Creo que el niño vive en un país que tiene muchos conflictos. Eso afecta a su familia y a él, pues en sus ojos se puede ver el miedo y su pequeña mano sostiene firme el carteP' (S.K.S.B.). 'La imagen que yo he visto me hace impresionar que hasta los niños están pidiendo paz.para el mundo y nadie se conmueve con una actitud tan inocente" (R.S.). Pelos textos produzidos pelos alunos, percebemos que eles se posicionaram criticamente diante da imagem e expuseram suas interpretações de forma problematizada e colocaram um contexto social para o personagem representado na imagem.

Notamos que o discurso do aluno S.K.S.B. é socialmente localizado, pois faz referência, direta ou indiretamente, aos aspectos sociais, culturais, econômicos e ideológicos que perpassam a realidade vivida por eles. $\mathrm{O}$ trecho revela, nas palavras do aluno, que a imagem do cartaz representa uma realidade similar vivida no Brasil e, em particular, em Fortaleza, que vem sendo marcada por constantes situações de violência e privação de direitos humanos. Ademais, quando o aluno ressalta que ninguém se comove com a inocência de uma criança, o estudante transpõe a realidade da imagem e mostra como são construídos e concebidos os valores sociais, os quais estão atrelados ao crescente processo de "naturalização" da violência na sociedade capitalista brasileira.

Quanto à categoria distância social, Kress e van Leeuwen (1996, 2006) afirmam que, para se perceber esta categoria, deve-se examinar o plano de enquadramento do participante representado na imagem. Os autores apontam três planos: fechado (close shot), médio (medium shot) e o aberto (long shot). No primeiro plano, o enquadramento é mais próximo, incluindo a cabeça e os ombros do participante representado, como é o caso do texto imagético analisado neste estudo, em que o garoto se encontra em enquadramento close-up. Isso permite que o leitor/observador perceba as emoções do garoto da imagem, fazendo-nos sentir mais íntimos dele. Em contraposição, os autores argumentam que, quanto mais ampla for a imagem, nos planos médio e aberto, o(s) participante(s) representado(s) se torna $(\mathrm{m})$ mais distante(s), inclusive sentimentalmente, do leitor. $\mathrm{Na}$ análise, percebemos que muitos alunos se sensibilizaram com o garoto representado do texto multimodal. Com relação a este aspecto, a estudante L.C.L. se manifestou da seguinte forma: "Si yo estuviera en la guerra, me quedaría desesperada, porque yo pensaba que iría morir, entonces me quedaría lejos de mis amigos, familia, las personas que me gusta. Entonces yo soy contra la guerra" (L.C.L.). 
No fragmento da produção escrita da estudante, constatamos que a aluna construiu uma proximidade simbólica com o personagem representado na imagem e também ela se colocou na situação vivenciada por ele, de forma que a estudante se identificou e se projetou no contexto social da guerra de modo a sentir "desespero". Isso faz alusão à função interativa, pela qual o processo de aproximação foi construído entre o produtor do texto e o leitor/observador, que realmente se identificou com o garoto da imagem e se sensibilizou com a luta ou "causa" levantada no texto.

Outra categoria de análise da metafunção interativa de Kress e van Leeuwen (1996) é a perspectiva, que se apresenta como o ângulo ou ponto de vista pelos quais o participante representado na imagem é mostrado. $\mathrm{O}$ ângulo pode ser frontal, oblíquo e vertical. Os autores esclarecem:

Produzir uma imagem não envolve apenas a escolha entre 'oferta' e 'demanda' e a seleção de um determinado tamanho da estrutura da imagem, mas também, simultaneamente, a escolha de um ângulo, um 'ponto de vista', o que implica a possibilidade de expressar atitudes subjetivas dos participantes representados, humanos ou não. Ao tratar das 'atitudes subjetivas', não estamos dizendo que significa que estas atitudes são sempre individuais e únicas. Veremos que muitas vezes elas são atitudes socialmente determinadas. Mas elas estão sempre codificadas como se fossem subjetivas, individuais e únicas (KRESS; VAN LEEUWEN, 1996, 2006, p. 129)3

No que diz respeito à percepção de ângulos, ressaltamos que, no ângulo frontal, prevalece o envolvimento afetivo do observador em relação ao participante representado, engendrando uma relação de igualdade. No oblíquo, o produtor tenta passar uma sensação de alheamento e deslocamento, conforme Almeida (2008). No plano vertical, "o produtor da imagem e o participante interativo exercem poder sobre esse objeto" (ALMEIDA, 2008, p. 21). No texto multimodal analisado, apesar de o garoto estar na parte baixa da imagem, ele direciona o olhar diretamente

\footnotetext{
3 'Producing an image involves not only the choice between 'offer' and 'demand' and the selection of a certain size of frame, but also, and at the same time, the selection of an angle, a 'point of view, and this implies the possibility of expressing subjective attitudes towards represented participants, human or otherwise. By saying 'subjective attitudes', we do not mean that these attitudes are always individual and unique. We will see that they are often socially determined attitudes. But they are always encoded as though they were subjective, individual and unique" (KRESS; VAN LEEWEN, 1996, 2006, p. 129).
} 
para os possíveis leitores/observadores, tentando passar a sensação de proximidade e um sentimento de igualdade. Sobre esse olhar, temos os seguintes fragmentos das redações: "El niño de la imagen tiene en su mirada un pedido a favor de la paz [...] Nosotros tenemos que mirar todas las posibilidades de intentar ayudar a estos jóvenes a vencer esa guerra contra las drogas, pues solo ellos pueden vencer esa batalla" (R. C.). "La gente va a expresar sus doloresy angustias con lo que está sucediendo en la ciudad, intentando asi llamar la atención de los gobiernos, llevando a sus hijos porque ellos creen que es una forma mayor de apelación debido a sus ojos inocentes que llevan el futuro de su país" (L.L.).

$\mathrm{Na}$ análise do corpus, percebemos que a maioria dos alunos se sensibilizou e se identificou com o garoto, focando no argumento do olhar apelativo da criança, que instiga uma reação do leitor. Vários alunos chegaram a se equiparar com ele por meio dos sentimentos de tristeza, pena e indignação. Metade dos alunos empregou, em suas redações, verbos na primeira pessoa do plural, o que enfatiza esse sentimento de identificação em relação ao garoto, como se eles pertencessem ao mesmo grupo. No entanto, a minoria enfatizou a inocência da criança contraposta à maturidade precoce em decorrência da guerra e da violência. Essas interpretações podem se relacionar às dimensões afetiva e crítica que Callow (2006) relaciona ao letramento visual/multimodal, pois a imagem pode causar essa aproximação ou distanciamento com o leitor/observador, bem como o posicionamento crítico advém justamente dessa postura de questionar e de apontar problemas na sociedade como é o caso da violência.

A modalidade, no texto imagético, vincula-se ao valor de verdade, o que pode ser representado de modo natural ou imaginário, segundo os autores da GDV. São mecanismos de modalização das imagens: a utilização da cor (saturação, diferenciação e modulação da sombra); contextualização (técnicas de perspectiva e profundidade); iluminação (presença ou ausência de iluminação) e brilho (desde o nível mais alto de brilho até os tons de cinza). Compreendemos que, na imagem analisada, há alto nível de modalidade, alta saturação de cores, cenário com plano de fundo desfocado e grande luminosidade e brilho. Tais aspectos tornam a imagem muito real, o que causa a seguinte reação: "El sentimiento que tengo delante tal imagen es una grande dolor como un bueco en mi corazón o como una pelea en mi alma. El niño pide el fin de la guerra, un punto final en una historia de horror. Él lucha contra la realidad, contra el lado oscuro de las personas"(L.S.D.). Acreditamos que a imagem passou muito valor de verdade, uma vez que a aluna usou palavras fortes como 
dor (dolor), guerra e horror. O que mostrou uma aproximação à realidade apresentada no texto multimodal.

$\mathrm{Na}$ função composicional, para Kress e van Leeuwen (1996, 2006), há a combinação entre elementos visuais de uma composição (imagem), ou seja, elementos interativos e representacionais são integrados em uma composição, para que ela faça sentido. Os significados dos elementos de uma composição são explicados, segundo os autores, por meio de três sistemas inter-relacionados: valor informacional, saliência e estruturação/enquadre.

Quanto à primeira categoria, o valor da informação diz respeito ao posicionamento dos elementos dentro da composição visual, podendo ser esquerda/direita, topo/base e centro/margem. Considerando esses tipos de posicionamentos, o participante representado, o garoto, ocupa quase toda a página da imagem, seu rosto está um pouco à esquerda, mas seu corpo se encontra centralizado e à base da imagem. No topo, está a frase "No a la guerra" (Não à guerra) como sendo a informação ideal ou promessa.

A saliência refere-se à ênfase maior ou menor na imagem, em detrimento de outros componentes imagéticos. No texto multimodal em foco, percebemos que há preponderância ou saliência da figura do garoto como elemento de apelo social ou chamamento para uma reflexão políticosocial.

A estruturação está vinculada à presença ou não de objetos interligados, ou melhor, é o modo como os elementos estão conectados. $\mathrm{Na}$ imagem analisada, existe uma ligação entre o menino e o cartaz com o pedido de paz. Sobre a estruturação do texto multimodal, observamos que poucos alunos enfatizaram a relação existente entre o menino (participante representado e esboço da linguagem visual) e o cartaz (linguagem verbal), o que nos faz refletir que a relação texto-imagem para os alunos ainda precisa ser mais bem desenvolvida. Em contrapartida, todos os alunos perceberam a saliência dada à criança e comentaram em seus textos, conforme o exemplo seguinte: "Veo un niño con la edad de cinco o seis años, que protesta contra la guerra, segura un cartel con firmeza y mira una persona que saca su foto, su expresión se confunde. Creo que no sabe lo que realmente está sucediendo. Siento que es una declaración por niños inocentes que sufren con la guerra, que se quedan indefensos, buérfanos con la muerte de sus padres" (E.F.).

Com relação à estruturação, houve alunos que imaginaram em que contexto se passou aquela cena, dentre estes, alguns educandos mencionaram a realidade internacional e especificaram a realidade social 
da Espanha. Outros abordaram a situação de altos índices de violência além de outros problemas sociais (desemprego, injustiça, tráfico de drogas, corrupção por parte dos políticos, uso abusivo de álcool e drogas, dentre outros) no Brasil. É possível perceber, também, que os estudantes acionaram seus conhecimentos prévios de história e de atualidades para interpretar o texto multimodal. O fragmento, a seguir, leva-nos a esse ponto da análise: "Para los españoles, la guerra civil se ha pasado por la historia, pero el recuerdo que de ella se queda es la deshumanización y la espantosa violencia que generó"(A.C.A.).

Somente um aluno fez a relação entre a imagem e o título da unidade 5 do livro Aula Internacional, "Basta ya - redactar un manifiesto a favor de la igualdad de la mujer" (SORIANO, 2006, p. 41). Colocamos, aqui, o fragmento do aluno, para enfatizar nossa argumentação: "Hoy en día muchas ciudades españolas están haciendo manifestaciones a causa de tanta desigualdad y la guerra, la gente sale a las calles a protestar, incluso a favor de la igualdad de la mujer" (L.L.). Isso evidencia que os alunos priorizaram os elementos imagéticos em suas análises em detrimento do componente textual, o que nos motivou a trabalhar, nas aulas posteriores, com os alunos, o desenvolvimento do letramento visual/multimodal em especial no que concerne a relação texto-imagem.

No texto multimodal, há a possibilidade de muitas interpretações. Por isso, os alunos abordaram várias questões sociais, que fazem parte, direta ou indiretamente, da rotina deles e das suas práticas sociais. Um dos alunos fez uma crítica social mais densa sobre a realidade contemporânea, ele escreveu que o personagem representado poderia ser um brasileiro que houvera perdido um parente próximo, em decorrência do uso abusivo de drogas ilícitas e do tráfico de entorpecentes.

Uma das alunas expressou, em seu texto, elementos imagéticos por meio de duas figuras, uma esboçando um conjunto de crianças em situação de baixa renda estudando, sentadas no chão de uma escola e a segunda trazia o desenho de crianças brincando de mãos dadas. Com isso, a aluna respondeu à atividade usufruindo de dois textos imagéticos, para, justamente, passar a ideia de que a criança é portadora de direitos humanos, como a educação e o lazer, além de fazer uma crítica social às condições precárias do ensino público em nosso país. Percebemos, também, que ela modalizou sua composição escrita, ao usar três cores distintas (azul claro, azul escuro e vermelho). Em vermelho, ela destacou "Orfanato no. Queremos nuestros padres vivos” (E. F.), como se fosse a voz das crianças com o intuito de abordar a questão da violência, tão presente em nosso cotidiano. 
Com base nas análises dos textos dos alunos, percebemos que as três metafunções estão presentes e se entrelaçam na construção de sentidos do texto multimodal. Além disso, as produções escritas revelaram o letramento visual crítico dos alunos, o que repercutiu em consideráveis críticas e questionamentos acerca da sociedade contemporânea, em especial, à cearense.

As análises revelaram que os alunos, ao construírem sentidos, compararam os aspectos sociais e histórico-culturais, presentes no texto multimodal, com a realidade vivenciada pela maior parte deles em seu cotidiano. Esse fato mostra como os alunos ressignificam o texto multimodal com base no conhecimento de mundo e nas experiências pessoais, e com base nos elementos da imagem, revelando-se, por exemplo, indícios de letramento visual dos alunos, mesmo que eles não tenham conhecimento e consciência da metalinguagem da Gramática do Design Visual para se entender estruturas visuais. Dessa forma, concluímos que o texto multimodal, constituído por linguagem verbal e linguagem visual, quando explorado em sala de aula de língua estrangeira, proporciona oportunidades de práticas de letramento ao aluno, que se sente estimulado para se posicionar diante dos textos que estão presentes nos contextos da sala de aula e que circulam na contemporaneidade.

\section{Considerações finais}

Procuramos, nesta pesquisa, investigar como os alunos, no contexto de aprendizagem de Língua Espanhola, constroem sentidos de um texto multimodal, ao escreverem suas impressões do texto lido e as referências que fazem a ele. Os educandos se deixaram envolver pelo texto multimodal e, não só praticaram as habilidades escrita e leitora, como as análises mostraram, também, que a maioria deles construiu um pensamento críticoreflexivo acerca da práxis social, dando, inclusive, sugestões de mudança para a sociedade em que estão inseridos.

Em relação à análise do corpus, percebemos que a maioria dos alunos mostrou o uso das três metafunções simultaneamente, na construção dos sentidos. Porém a função interativa foi enfatizada em suas interpretações, quando eles se identificaram, afetivamente, com a criança (participante representado), ressaltando o olhar de demanda do ator da imagem. Os estudantes salientaram a análise do componente visual-imagético, em detrimento do elemento verbal, o que denota o poder de influência e 
persuasão da imagem sobre a(s) leitura(s) desses estudantes. Isso aponta para a riqueza do texto multimodal como ferramenta pedagógica para o ensino de idiomas.

Devemos ressaltar, portanto, que a atividade empregada, neste relato de experiência, é um dos muitos exemplos de como nós, professores, podemos trabalhar com textos multimodais, uma vez que estamos aptos a usá-los por meio de, por exemplo, dinâmicas de grupo sobre uma determinada temática; construção de novos textos imagéticos por parte dos alunos, para vender um produto ou uma ideia; autoprojeção sobre o participante representado, para dar continuidade a uma narração; dentre outras. Com base no posicionamento dos estudantes, diante desta e de outras atividades, o professor poderá tornar a aula mais dinâmica, atrativa e interessante, bem como promover a oportunidade a seus alunos de desenvolverem suas habilidades interpretativas e sua competência leitora visual, o que possibilitará um ganho quanto ao conhecimento teórico, além de fomentar o trabalho com a autoestima dos estudantes, de um modo geral.

\section{Referências}

ALMEIDA, D. B. L. de. Do texto às imagens: as novas fronteiras do letramento visual. In: PEREIRA, R. C.; ROCA, P. (orgs.). Linguística Aplicada - um caminho com diferentes acessos. São Paulo: Contexto, p. 173-202, 2009.

BAMFORD, A. The visual literacy white paper. University Technology Sydney. 2003.

CALLOW, J. Reading the visual: an introduction. In: CALLOW, J. (org.). Image matters - visual texts in the classroom. Newtown, Australia: PETA, p. 1-13, 1999.

CALLOW, J.. Literacy and the visual: Broadening our vision. In: English teaching: Practice and Critique, vol. 4, n. 1, p. 6-19, 2005.

CALLOW, J. Images, politics and multiliteracies: using a visual metalanguage. Australian Journal of Language and Literacy. v. 29, n. 1, p. 07-23, 2006.

CALLOW, J.. The shape of text to come - how image and text work. PETAA, 2014.

COPE, B.; KALANTZIS, M. (eds.). Multiliteracies - Literacy learning and the design of social futures. New York/London: Routledge, 2000.

FERNANDES, J. D. C.; ALMEIDA, D. B. L. de. Revisitando a Gramática Visual nos cartazes de guerra. In: ALMEIDA, D. B. L. de (org.). Perspectivas em Análise Visual: do fotojornalismo ao blog. João Pessoa: Editora da UFPB, p. 11-31, 2008. JEWITT, C. (ed.). The Routledge Handbook of Multimodal Analysis. London, New York: Routledge, 2009. 
KLEIMAN, A. Modelos de letramento e as práticas de alfabetização na escola. In: KLEIMAN, A (org.). Os significados do letramento: uma nova perspectiva social da escrita. Campinas, SP: Mercado das Letras, p. 15-61, 1999.

KRESS, G.; VAN LEEUWEN, T. Reading images: the grammar of visual design. London, New York: Routledge, [1996], 2006.

KRESS, G. Literacy in the New Media. London: Routledge, 2003.

LANKSHEAR, C.; KNOBEL, M. New literacies: Changing knowledge and classroom learning. Buckingham, PA: Open University Press, 2003.

LAVILLE, C.; DIONE, J. A construção do saber: manual de metodologia da pesquisa em ciências humanas. Adaptação de Lana Mara Siman. Porto Alegre: Artmed, 1999.

LEMKE, J. L. Letramento metamidiático: transformando significados e mídias. Campinas, SP: 2010. Disponível em: http:/www-personal.unich. edu/ jaylemke/jll-new.htm. Acesso em: 14 abr. 2011.

ROJO. R. H. R. Pedagogia dos Multiletramentos. In: ROJO, R. H. R.; MOURA, E. (Orgs.). Multiletramentos na escola. São Paulo: Parábola Editorial, p. 11 $31,2012$.

SERAFINI, F. Reading the visual: An introduction to teaching multimodal literacy. New York: Teachers College Press, 2014.

SOARES, M. Letramento: um tema em três gêneros. $2^{\mathrm{a}}$ ed. Belo Horizonte: Autêntica, 1998.

SORIANO, C. et al. Aula Internacional 3. Barcelona: Difusión, 2006.

STOKES, S. Visual literacy in teaching and learning: A Literature perspective. In: Eletronic Journal for the Integration of Techonology in Education. v.1, n.1, p. 10-19, 2002.

THE NEW LONDON GROUP. A pedagogy of Multiliteracies designing social futures. In: COPE, B.; KALANTZIS, M. (eds.) Multiliteracies - Literacy learning and the design of social futures. London: Routledge, 1996.

VAN LEEUWEN, T. Multimodality. In: SIMPSON, J. (ed.). The Routledge Handbbok of Applied Linguistics. New York/London: Routledge, p. 668-682, 2011.

WALSH, M. Multimodal literacy: researching classroom practice. Australia: Primary English Association, 2011.

WILEMAN, R. E. Visual communicating. Englewood Cliffs, N.J.: Educational Technology Publications, 1993.

Data de submissão: 17/01/2016. Data de aprovação: 11/04/2016. 